Dante's, as baihua and wenyan are varieties of a written language. But if we take into account the social tone of a language, Hu Shi's comparison is not that farfetched. The key word here is diglossia, a term frequently used by social linguists. Charles Ferguson defines diglossia as the functional distinction between two language varieties, one called the high language and the other the low language, and he refers to premodern Europe and premodern China as two typical diglossic communities. In a clear linguistic labor division, Latin and wenyan function as high languages, and Italian and baihua function as low languages. While it is true that the best premodern Chinese fiction writers, in command of several language registers (classical Chinese, vernacular, and local dialect), frequently created an intermediate language by alternating or mixing the classical and the vernacular, those writers were clear about the social decorum demanded by the diglossic situation when operating in different linguistic registers. The existence of such an intermediate language certainly undermined the conventional linguistic hierarchy, but the real overthrow didn't become possible until the May Fourth period, when baihua assumed its political importance as the national language and the language of the future.

My sense is that a comparison of wenyan versus baihua and Latin versus Italian can be meaningful and fruitful. Renaissance Europe and early-twentieth-century China both witnessed a breakdown of a long-lasting diglossic situation, which brought about tremendous linguistic turmoil and drastic changes in the linguistic hierarchy and in language attitudes. I have been working on a project that examines how writers in these two historical contexts navigate linguistic complexities, juggling different languages. While there has been an increasing awareness about multilingualism and heteroglossia in recent years, overall literary history is still written according to the die-hard monolingual model. Systematic research into those historical moments when literature has to be redefined as a result of language change and language competition is much needed.

Moreover, Hu Shi's advocacy of the vernacular not only connects the Chinese Renaissance with the European Renaissance but also firmly places the Chinese Renaissance among other Re- naissances being created and promoted in lands outside Europe. Since 2003, I have been coediting (with Brenda Schildgen and Sander Gilman) a volume of essays entitled Other Renaissances, which examines how the term renaissance was reinvented and reimagined in various nonEuropean contexts. Many "Other Renaissances" (for instance, the Indian, Irish, Hebrew, Arab, and Maori Renaissances) that were called into being by non-Europeans (or by Europeans excluded from mainstream European culture) were centered on language revolution. We see in those historical moments the breakdown of conventional linguistic hierarchy and the transformation of a certain language. In other words, $\mathrm{Hu}$ Shi is certainly not the only one passionate about renaissance and about vernacular. The emergence of Other Renaissances and vernaculars played a significant role in many countries' pursuit of modernization and national independence.

I thank DeFrancis for giving me the opportunity to clarify my thoughts on issues of vernacular and renaissance. Both terms offer a unique perspective to reframe our current understanding of world literature and world history.

Gang Zhou

Marina, CA

\section{How Free Is the War Photographer?}

\section{To THE EDITOR:}

Judith Butler's "Photography, War, Outrage" (120 [2005]: 822-27) rightly points to the sinister implications of the phenomenon of "embedded" journalists in the 2003 invasion of Iraq and implicitly gestures to the importance of this issue for scholars and teachers in the humanities who work around questions of representation and interpretation. However, I am concerned that one strand of Butler's argument overstates the case for the journalists' helplessness. Butler disagrees with Susan Sontag's position that "the photograph cannot by itself provide an interpretation" (823), pointing out-correctly, in my view-that photographs are always interpretations, because what one chooses to show and how one chooses to show it will vary from one photographer to the next. But Butler simultaneously seems to assume that 
when embedded reporters travel "only on certain trucks, [look] only at certain scenes, and [relay] home only images and narratives of certain kinds of action" (822) the meaning and interpretation of these reporters' work is perforce predetermined. There is no acknowledgment that the subject matter alone of an image is not the only determinant of that image's meaning-that one can present the same object from varying points of view. The embedded journalists may, for instance, be permitted only to photograph certain soldiers, but the way they photograph these soldiers (camera angle, distance of subject from the viewer, sharpness of image, positioning of subject, film speed, process of film developing, etc.) can drastically alter viewers' perceptions of the subject (for example, a low angle may make subjects appear domineering, while a high angle may make them appear vulnerable).

Perhaps it is key to keep in mind here that the word perspective encloses multiple meanings. When Butler defines "embedded reporting" as "the situation in which journalists agree to report only from the perspective established by military and governmental authorities" (822; my emphasis), she must be referring to the literal perspective of the reporters (what they will see, which way they will face). Journalists do not agree to report the ideological perspective of the military and government, and even if they do, such a commitment would be difficult to enforce by either the journalists or by those who have demanded such a commitment-as scholars who work with texts of all kinds know only too well, the vagaries of interpretation make it impossible for readers to reach a consensus on whether a supposed intention has been fulfilled, and in any case representations across the spectrum of media often escape their creator's "intention." In short, Butler doesn't seem to allow for the possibility of embedded reporters reporting against the grain, as it were, and if they do not, of readers, viewers, and listeners actively interpreting the journalists' texts against the grain. Scholars in many fields have shown how creators of music, images, and words who were and are subject to various explicit and implicit regimes of censorship have been able to manipulate tone and use rhetorical and literary devices like irony, understatement, overstatement, and metaphor to undermine attempts to predeter- mine the meanings of their representations. It may be possible to control what one sees and what one represents, and it may be possible to socialize people to see and represent a certain way, but it is impossible to completely control the unpredictabilities of thought, imagination, and desire, to completely control how one sees and how one represents what one sees. To believe that such complete control is possible not only would deny any agency for the embedded journalists and relieve them of any responsibility to use their embedded positions critically but would also deny readers agency and responsibility to read critically. In the end, Butler seems to ascribe to photography (both the process and the product) the same transparency that she critiques Sontag for insisting on.

Ian Barnard California State University, Northridge

\section{Reply:}

I very much appreciate Ian Barnard's response to my short essay "Photography, War, Outrage." I especially welcome the chance to think more precisely about whether embedded reporting "predetermines" the meaning and interpretation of visual and narrative reporting of the war. The term predetermine occurs in Barnard's summary of what I have written, but it does not appear in the essay itself. He is right to argue that the subject matter of an image is not the determinant of that image's meaning, and I am, as it were, riding on the same truck with him on this point. He is surely also right to maintain that "the way" photographers shoot a scene, even within the parameters of embedded reporting, can vary. When he argues that I don't allow for embedded reporters reporting "against the grain," I find myself amused to be accused of not seeing that there are subversive ways to occupy and resignify the norm. So let me clarify two points that will, I hope, make clear in what this disagreement consists.

First, the questions that guide my inquiry into embedded reporting-as well as a separate piece on the Abu Ghraib digital images-are the following: how do the norms that govern which lives will be regarded as human lives and which will not enter into the frames through which discourse and 